\title{
CIDADE ACESSÍVEL: CONDIÇÃO DE POSSIBILIDADE PARA O EXERCÍCIO DA CIDADANIA
}

\author{
Dirceu Lemos Silva ${ }^{1}$ \\ Clarissa Marques $^{2}$
}

Resumo: O presente artigo parte da constatação que ao longo da história a pessoa com deficiência fora segregada da sociedade capitalista por não fazer parte de um modelo de produção. A experiência da deficiência não é resultado de uma lesão e, sim, de um ambiente hostil à diversidade. Eis a necessidade de analisar a acessibilidade nas cidades como condição para a cidadania, como condição para inclusão.

Palavras-chave: Cidade, Acessibilidade, Cidadania, Diversidade, Inclusão social.

\section{ACCESSIBLE CITY: CONDITION OF POSSIBILITY FOR THE EXERCISE OF CITIZENSHIP}

\begin{abstract}
The present article is based on the fact that throughout history the disabled person has been segregated from capitalist society for not being part of a model of production. The experience of disability is not the result of an injury, but an environment hostile to diversity. This is the need to analyze accessibility in cities as a condition for citizenship, as a condition for inclusion.
\end{abstract}

Keywords: City, Accessibility, Citizenship, Diversity, Social inclusion.

\section{INTRODUÇÃO}

A perspectiva comunitária dos direitos fundamentais torna-se mais evidente quando em análise os direitos de terceira dimensão, representados pela indeterminação do sujeito em razão de sua transindividualidade. Tal dimensão difusa surge após a experiência de duas guerras mundiais, instituindo-se o debate acerca da solidariedade presente no âmbito de certos direitos fundamentais, como o direito à proteção do meio ambiente, tendo em vista a necessária atuação

\footnotetext{
${ }^{1}$ Mestre em Historicidade dos Direitos Fundamentais pela Faculdade Damas da Instrução Cristã - FADIC, Especialista em Direitos Humanos pela Universidade Católica de Pernambuco - UNICAP, Advogado. ${ }^{2}$ Pós-Doutorado realizado na The New School of Social Research-NY (Bolsista CAPES), Doutora em Direito pela UFPE (Estágio de Doutorado realizado na Universidade de Paris - Bolsista CAPES), Professora do PPGD da Faculdade Damas ARIC/PE, da Universidade de Pernambuco-UPE e da FACIPE/NUFA, Coordenadora do Grupo de Estudos e Pesquisas Transdicisplinares sobre Meio Ambiente, Diversidade e Sociedade - GEPT/UPE, Advogada ambiental.
}

Rev. de Direito Urbanístico, Cidade e Alteridade | e-ISSN: 2525-989X | Maranhão | v. 3 | n. 2 | p. 88 - 103 | Jul/Dez. 2017. 
cooperada (inclusive internacionalmente), para que os valores fundantes dos referidos direitos alcancem a consagração desejada. Eis porque falar em solidariedade. A ação isolada deixa de ser suficiente e as circunstâncias passam a exigir um agir solidário por meio de atos e decisões comunitárias e um comportamento ético também solidário. Isso se dá em razão de que os efeitos da promoção, ou não, dos direitos difusos também serão sentidos por um número indeterminado de pessoas, incluindo-se dentre estas, as que ainda estão para existir, as futuras gerações.

Somado a isso, com a emergência de novos direitos a noção de cidadania sofre uma ampliação. Percebe-se que nas últimas décadas, a cidadania voltou-se com maior atenção para a conquista dos direitos relacionados a interesses coletivos e difusos. É no âmbito desse direito ao meio ambiente, envolvido pelo ideal solidário que se encontra a discussão sobre cidades acessíveis.

O processo de urbanização experimentado na maioria das cidades deu-se de forma abrupta, negando a natureza e construindo cidades que representam verdadeiros templos de desigualdade e exclusão; um espaço fragmentado e propenso a conflitos que segrega aquele que não tem como pagar pela porção de cidade que almeja viver e, então, é condicionado, conduzido ou melhor, disciplinado a aceitar o que lhe é imposto como normal. É nos aglomerados urbanos que as barreiras físicas, atitudinais e sociais apresentam-se como uma forma contundente de desrespeito ao direito fundamental à cidade acessível. Nesse sentido, questiona-se: a não efetivação do direito fundamental à cidade acessível representaria óbice a uma vida plena, digna e autônoma por parte das pessoas com deficiência, dificultando, assim, o exercício da cidadania?

Ao longo da história, a deficiência foi percebida como coisa sobrenatural e tratada como ameaça social e as pessoas deficientes foram excluídas da sociedade, a exemplo do que ocorria com os loucos, leprosos ou aqueles considerados delinquentes. Observa-se que a pessoa com deficiência fora segregada de uma sociedade capitalista por não fazer parte de um modelo de produção, estando, portanto, na mira de uma sociedade disciplinar. Nesse sentido, a experiência da deficiência não é resultado unicamente de uma lesão, mas do ambiente social hostil à diversidade física. A lesão é um dado isento de valor, ao passo que a deficiência é o resultado da interação de um corpo com lesão em uma sociedade discriminatória, planejada para segregar os "desvios" da norma. Desta forma, foi utilizada no presente trabalho uma metodologia majoritariamente analítica, aliada a uma abordagem exploratória que inspirou-se 
na perspectiva histórica da deficiência, sem contudo esquecer a crítica em nome de uma história não-linear, como base explicativa para o cenário identificado no texto.

\section{HISTORICIDADE, CIDADE E EXCLUSÃO}

O historicismo tradicional nega o problema crítico do conhecimento histórico como fruto da sociedade, "ocultando-se no suposto mito da neutralidade do saber e da universalidade dos princípios da ciência positivista" (WOLKMER, 2004a, p. 16); marcado, portanto, por uma tradição metodológica que baseia-se em "proposições revestidas pela força da continuidade, da previsibilidade, do formalismo e da linearidade" (WOLMER, 2004a, p. 11). A "história tradicional" ou "história positivista", que teve seu ápice no século XIX, pretende-se "objetiva" e "neutra", "por acreditar que os fatos podem ser isolados do sujeito que os confronta (o historiador) e podem ser percebidos em seus contornos precisos", assim, teria "a capacidade de descrever a verdade sobre os fatos históricos", já que para tal corrente, a análise do objeto pode ser assimilada pela ciência positivista sem que haja qualquer prejuízo, de tal modo, "o saber histórico tem a capacidade de reproduzir fielmente os fatos históricos" (FONSECA, 2012, p. $57)$.

A falácia da neutralidade cai por terra quando observa-se que essa historiografia fundada na neutralidade axiológica assumiu o contorno de "história universal", ou, "história geral", portanto, uma historicidade excludente. É o historiador, subjetivamente, que pinça quais fatos históricos são relevantes e quais são preteridos, de modo que, a história positivista "tende a distanciar-se da dinâmica histórica efetiva, procedendo a um conhecimento presentista ou retrospectivo" (FONSECA, 2012, p. 60).

A história progressista ${ }^{3}$ promove a sacralização do presente, que passa a ser glorificado como meta e proposta universal, por considerar-se que o modelo atual, leia-se, o modelo ocidental contemporâneo, representa o apogeu histórico de um modelo de organização política e jurídica para as sociedades (HESPANHA, 2012, p. 20). A linearidade construída pelo historiador torna-se grave distorção do passado, pois é definida a partir do presente, ou seja, pertence à época do historiador e não à época estudada (FONSECA, 2012, p. 61). Essa visão

\footnotetext{
${ }^{3}$ António Manuel Hespanha esclarece a ideia que a história pode servir para provar a linearidade do progresso, como querem alguns. Para tanto, o autor destaca que, partindo-se de um modelo histórico evolucionista, ou seja, um modelo que conceba a história como acumulação progressiva de conhecimento, o direito também poderia ser visto como algo em evolução, passando de uma fase juvenil, rude, para a fase atual, de "apogeu", o que se daria através do progresso da sabedoria humana e das descobertas de eméritos juristas (HESPANHA, 2012, p. 19).
}

Rev. de Direito Urbanístico, Cidade e Alteridade | e-ISSN: 2525-989X | Maranhão | v. 3 | n. 2 | p. 88 - 103 | Jul/Dez. 2017. 
anacrônica, ao reduzir a história a um encadeamento de fatos, identifica outra consequência do “historicismo”, que é a exclusão. No dizer de Ricardo Marcelo Fonseca (2012, p. 60),

(...) na medida em que a história é vista como uma sequência linear e harmônica de fatos, que se encadeiam de modo lógico no tempo, está-se elaborando, na verdade, uma lógica da exclusão de todas as perspectivas e possibilidades históricas, ocorridas ou frustradas, mas que acabaram ficando ao largo do projeto que regeu o encadeamento dos fatos eleitos.

O modo de encarar a temporalidade de forma aparentemente lógica, coerente, linear ${ }^{4}$ e harmônica tem por consequência natural ser excludente. Verifica-se, desta feita, que a exclusão no discurso da historiografia tradicional é reflexo da exclusão que existiu/existe na realidade histórica, "que é feita de um processo contínuo de conflitos, de lutas e de exclusões" (FONSECA, 2012, p. 155/156). Na busca por uma "nova História" mister estabelecer qual perspectiva histórica rejeita-se, bem como, qual historicidade pretende-se alcançar, em outras palavras, necessário se faz romper com o modelo tradicional de historicidade que serviu para justificar e consubstanciar a atuação estatal e buscar uma historicidade que se preste a refletir, modificar e recriar a cotidianidade.

A nova História é plural, não privilegia o discurso vencedor, mas sim as diversas vozes que compõem o fato histórico, dá notoriedade ao cotidiano, ou seja, a atividade humana. Nesse sentido, passa-se a repensar a historicidade sob nova ótica: quais acontecimentos foram narrados e quais foram esquecidos, quais vozes foram ouvidas e quais foram silenciadas, quais fontes históricas foram aclamadas e quais foram renegadas.

Daí acreditar-se que a cidade, enquanto objeto da "ciência da cidade", não pode ser a cidade histórica, pelo menos não nessa pesquisa. Em que pese a representatividade e influência dos clássicos, esses textos afastam a cidade enquanto objeto da ciência, por perfazerem uma cidade histórica remontada a partir de fragmentos, ganhando ares de documento, de exposição ou peça de museu (LEFEBVRE, 2001, p. 106). "A cidade historicamente formada não vive mais", isso é o que se observa da obra de Lefebvre. O autor esclarece que a cidade histórica não passa de um objeto de consumo cultural para os turistas e para o "estetismo". No entanto, destaca que “o urbano” persiste (LEFEBVRE, 2001, p. 106).

Em mais um salto histórico, convém destacar que as crises de superacumulação voltam a assolar o capitalismo, aqui nos referimos aos anos 90 do século XX e início desse século. A

\footnotetext{
${ }^{4}$ A temporalidade linear representa um tempo vazio e homogêneo, onde só existe lugar para a soma (encadeada) de fatos como se o tempo fosse um receptáculo com forma e tamanho bem definidos. Há uma exclusão de todas as virtualidades históricas e todas as experiências passadas que não foram registradas ou que foram frustradas, e somente há espaço, em tal historiografia, para os sucessos históricos (FONSECA, 2012, p. 155).
} 
urbanização mais uma vez apresenta-se como saída e causa da crise, em especial quando recordamos o boom do mercado imobiliário ${ }^{5}$ e suas consequências para urbanização e o modo de vida urbano. A explosão imobiliária fora testemunhada por quase todas as cidades, essa globalização se deu de forma parecida, sendo os ricos favorecidos em detrimento de milhares de miseráveis, que se viam obrigados a migrar, "a medida que o campesinato rural era desapropriado pela industrialização e comercialização da agricultura" (HARVEY, 2014, p. 42/43).

O processo atual de urbanização, como nas fases já mencionadas, mas agora em caráter global $^{6}$, trouxe consigo inúmeras transformações no estilo e qualidade de vida da urbanidade. O acesso ao espaço é de quem por ele possa $\operatorname{pagar}^{7}$, essa é a premissa do espaço moderno, configurado por elites econômicas que escolheram o isolamento e assim pagam por ele de bom grado (BAUMAN, 1999, p. 24). O resultado dessa crescente polarização na distribuição de renda e de poder é evidenciado nas formas espaciais de nossas cidades; esse desenvolvimento incoerente só evidencia e enfatiza que cada vez mais vivemos em cidades divididas, fragmentadas e propensas a conflitos (HARVEY, 2014, p.47/48).

\section{NA BUSCA POR UMA FUNDAMENTAÇÃO ÉTICA: SOLIDARIEDADE PARA ALÉM DA TOLERÂNCIA}

A questão das cidades é um construído histórico de segregação, onde identifica-se que o planejamento urbano não observou as particularidades das pessoas, o que chamamos de respeito às diferenças, tendo tratado a todos, como o outro genérico, o indivíduo abstrato do universalismo dos ditos direitos humanos. Ou ao observar tais particularidades, o olhar deu-se no intuito de excluir o outro, o diferente, o "anormal".

Ao reconhecermos a diversidade e assegurar tratamento específico, resta insuficiente tratar o indivíduo de forma genérica, geral e abstrata, fazendo-se necessário, "a especificação do sujeito de direito, que passa a ser visto em sua peculiaridade e particularidade" (PIOVESAN,

\footnotetext{
${ }^{5}$ Quanto ao boom do mercado imobiliário, vide: HARVEY, 2014.

${ }^{6}$ A respeito da globalização, com lucidez, nos fala Zygmunt Bauman: “O significado mais profundo transmitido pela idéia da globalização é o do caráter indeterminado, indisciplinado e de autopropulsão dos assuntos mundiais; a ausência de um centro, de um painel de controle, de uma comissão diretora, de um gabinete administrativo. A globalização é a "nova desordem mundial" de Jowitt com um outro nome” (BAUMAN, 1999, p. 58).

7 Para Ermínia Maricato (2013, p. 33): “A cidade constitui um grande patrimônio construído histórico e socialmente, mas sua apropriação é desigual e o nome do negócio é renda imobiliária ou localização, pois ela tem um preço devido aos seus atributos".
}

Rev. de Direito Urbanístico, Cidade e Alteridade | e-ISSN: 2525-989X | Maranhão | v. 3 | n. 2 | p. 88 - 103 | Jul/Dez. 2017. 
2015b, p. 68). Nesse sentido, Flávia Piovesan, destaca que determinados sujeitos ou violações a direitos, exigem uma resposta específica e determinada. Para a autora, "as mulheres, as crianças, a população afrodescendente, os migrantes, as pessoas com deficiência, entre outras categorias vulneráveis, devem ser vistas nas especificidades e peculiaridades de sua condição social" (PIOVESAN, 2015b, p. 68).

$\mathrm{Na}$ busca por uma fundamentação ética do direito à cidade acessível como direito fundamental, deparamo-nos com um entrave, a titularidade desse direito. Assim, para além do reconhecimento do outro, o que seria facilmente resolvido através de uma retórica de tolerância, mister pensar a cidade para além do presente, para aqueles que não conhecemos, para uma geração futura de sujeitos ainda não nascidos, e para tanto, imperioso analisar o princípio da solidariedade como fundamentação ética para o direito aqui enfrentado. Diante de tais considerações é que se arrazoa sobre a fundamentação ética do direito à cidade acessível. Para tanto, a partir da crítica marxista aos direitos do homem de matiz abstrata, individualista e universal, é possível repensar uma concepção filosófica jurídica que se ocupe da realidade social e de uma práxis capaz de contemplar a emancipação do ser humano (WOLKMER, 2004b, p. 20).

Na contramão da ideia de ser o direito positivo um instrumento repressivo que legitima a manutenção das distorções econômicas e das injustiças sociais (WOLKMER, 2004b, p. 19), vislumbra-se o direito dogmaticamente organizado como garantidor de uma tolerância almejada, por ser o direito um sistema que diferencia-se do âmbito moral e religioso pelo esvaziamento de conteúdo ético prévio e por neutralizar os demais sistemas de orientação normativa (ADEODATO, 2010, p. 118).

Sobre a égide de um Estado Democrático e Social de Direito, observa-se que a tolerância desempenha importante função no enfrentamento das desigualdades. (ADEODATO, 2014, p. 43). Especificamente quanto à desigualdade ambiental o professor João Maurício (2010, p. 125) leciona que:

A desigualdade ambiental ocorre em relação ao meio em que vive o indivíduo, isto é,
se há condições de ter satisfeitos os constrangimentos de subsistência, saúde, abrigo,
educação estabilidade emocional etc. Como as respostas a esses constrangimentos
variam em tempo e espaço da história da humanidade e de casa ser humano, o
ambiente apresenta correspondente variação de oportunidades.

Neste liame, "como ambiente ético comum, o direito na sociedade complexa precisa propiciar a tolerância e reduzir os níveis de dominação de um ser humano por outro" (ADEODATO, 2014, p. 42). A esse respeito, pontua Adeodato (2010, p. 125), que, "tolerar as 
diferenças compensa a desigualdade". O cuidado e dever para como o outro, encontra respaldo ético na tolerância, para João Maurício Adeodato (2010, p. 117), "a tolerância constitui uma exigência ética construída historicamente no âmbito de algumas culturas específicas".

Quanto as acepções da palavra tolerância, destaca o autor,

\begin{abstract}
Note-se que a palavra tolerância não é entendida aqui apenas como "tolerar", em seu uso vulgar, mais fiel ao sentido primitivo de "suportar" algo desagradável. Significa, ao revés, a aceitação e o apoio recíproco a pessoas opiniões e atitudes oriundas de visões de mundo diferentes e não redutíveis umas às outras, principalmente religiões, ideologias e outros sistemas de orientação normativos. Diferentes e não redutíveis umas às outras significa dizer: potencialmente conflituosas (ADEODATO, 2010, p . 117-118).
\end{abstract}

Em suma, o significado da tolerância explanada na retórica do professor João Maurício Adeodato é corolário do reconhecimento da diversidade, não se admitindo a tolerância como suportar o outro, e sim, respeitar suas peculiaridades. Nesse sentido, "para além das razões de método, pode-se aduzir em favor da tolerância uma razão moral: o respeito à pessoa alheia". Nesse mesmo sentido assim posiciona-se Bobbio (2004, p. 191) quando destaca as razões para tolerância. Porém, como apontado por Adeodato, a retórica da tolerância é apenas uma sugestão no nível de retórica estratégica", "uma ética otimizadora e não descritiva, que pretende "racionalizar" e diminuir aborrecimentos e sofrimentos humanos em geral" (ADEODATO, 2014, p. 43).

Nessa perspectiva, constata-se que a "retórica da tolerância", por si só, não seria o bastante na busca por uma fundamentação ética para o direito à cidade acessível, em que pese assegurar o dever ético de respeito e reconhecimento para com o outro. Contudo, necessário se faz, fundamentar o dever de cuidado para além do outro, para as gerações futuras. Ou seja, é reconhecer o direito de sujeitos ainda não nascidos a um ambiente urbano sadio, sustentável e acessível.

Entendido como direito de terceira geração, o direito fundamental ao meio ambiente ecologicamente equilibrado abarca o direito à cidade, por ser a cidade a expressão mais latente da conjuntura de meios que compreendem o ambiente urbano. Para Celso Lafer (1988, p. 180),

\footnotetext{
${ }^{8}$ O professor João Maurício Adeodato irá trabalhar as dimensões da retórica em A retórica constitucional, onde, quanto a retórica estratégica, destaca que: “A retórica prática, ou estratégica, já é reflexiva, constitui um primeiro grau de metarretórica, uma retórica sobre a retórica material, que parte dela e a ela retorna para reconstituí-la, isto é, interferir sobre ela. Para chegar a essa práxis, a retórica estratégica precisa de uma doutrina, uma teoria, aquele conjunto de regras construídas a partir da observação da retórica dos métodos que tem por objetivo influir sobre eles e possibilitar sucesso a quem deles se utiliza. Ela observa como funciona a retórica material e verifica que fórmulas dão certo, construindo uma pragmática finalística e normativa da comunicação. É literalmente uma metodologia (teoria dos métodos) da retórica material.” (ADEODATO, 2010, p. 73).
} 
"estes direitos tem como titular não o indivíduo na sua singularidade, mas sim grupos humanos como a família, o povo, a nação, coletividades regionais ou étnicas e a própria humanidade”.

Os “direitos da nova geração" (BOBBIO, 2004, p. 209) são conquistas históricas na defesa das presentes e das futuras gerações onde ganha destaque a titularidade de direitos por sujeitos ainda não nascidos. A consagração dos chamados direitos difusos, fundamentais de terceira dimensão, depare-se com a mudança paradigmática no que diz respeito ao sujeito de direito, cuja maior contribuição foi instituir que o titular de tais direitos não precisa ser individualizado como era de costume até então e o valor da solidariedade surge como dever intrínseco à Ordem dos direitos fundamentais. Na Ordem dos direitos fundamentais, para além da marca da liberdade e da busca pela igualdade, a historicidade dos direitos fundamentais apresenta ainda um desejo pela solidariedade, de tal modo, o conceito de direitos fundamentais amplia-se, sendo agora marcado por direitos que exigem um dever solidário. Em outras palavras, não são apenas direitos, mas também deveres incumbidos a todos os titulares nessa ordem de direitos. (MARQUES, C., 2014, p. 160).

Destaque-se que, somente no final do século XIX o discurso da solidariedade aparece sobre uma nova ótica, que não mais se confunde com caridade ou filantropia. Essa perspectiva se traduz em uma nova maneira de pensar a sociedade, não mais como um sistema de proteção social (dever social), mas como um standard para construção de políticas sociais (FARIAS, 1998, p. 190).

\section{CIDADES ACESSÍVEIS COMO INSTRUMENTOS DE PROMOÇÃO DA CIDADANIA}

Por esses lineamentos doutrinários, o ambiente urbano apresenta-se como objeto de estudo, posto ser nos aglomerados urbanos que as barreiras arquitetônicas apresentam-se como forma mais voraz de desrespeito ao direito fundamental à cidade acessível e, porque não, ao direito fundamental ao meio ambiente ecologicamente equilibrado.

Para além do estigma de vulnerável/incapaz a pessoa com deficiência depara-se com barreiras físicas e estruturais quando se lança pela cidade, calçadas irregulares, sem rebaixamento ou rampas de acesso aos cadeirantes, falta de telefones públicos ou banheiros coletivos adaptados, entrada e saída de prédios públicos incompatíveis com a condição do deficiente, corredores, portas e elevadores fora das normas técnicas de acessibilidade, ausência

Rev. de Direito Urbanístico, Cidade e Alteridade | e-ISSN: 2525-989X | Maranhão | v. 3 | n. 2 | p. 88 - 103 | Jul/Dez. 2017. 
e desrespeito às vagas destinadas à pessoa com deficiência em estacionamentos, ausência de plataformas e/ou elevadores nos ônibus e demais meios de transporte coletivos, afora outras tantas estruturas que não são postas à disposição da pessoa com deficiência. De tal modo, a não efetivação do direito fundamental à cidade acessível representa óbice ao exercício de uma vida independente e digna por parte das pessoas com deficiência, dificultando, assim, o fortalecimento do paradigma da inclusão social.

Para construção da ideia de cidadania, incluindo-se o exercício dessa cidadania no ambiente urbano, mister as considerações tecidas a partir dos problemas jurídicos ocasionados pelo totalitarismo, por essa razão Hannah Arendt ressalta que o primeiro direito humano é o “direito de ter direitos", o que significa pertencer, pelo vínculo da cidadania, a algum tipo de comunidade juridicamente organizada e viver numa estrutura onde se é julgado por ações e opiniões, por obra do princípio da legalidade (LAFER, 1988, p. 212/213). Hannah Arendt também permeia a obra de Lindgren Alves (2005, p. 56), quando ao destacar a cidadania no mundo globalizado, define a cidadania como o pertencimento a uma comunidade disposta e capaz de lutar pelos direitos de seus integrantes.

Depreende-se da análise do caso dos apátridas, em pleno século $\mathrm{XX}$, que perder o status de cidadão, significa também, perder o status de humano, já que, "a privação da cidadania afeta substantivamente a condição humana, uma vez que o ser humano privado de suas qualidades acidentais - o seu estatuto político - vê-se privado de sua substância", perdendo assim, a qualidade substancial da condição humana, "que é de ser tratado pelos outros como um semelhante" (LAFER, 1988, p. 209).

"Estar situado em" e "pertencer a" são atributos complementares da cidadania, na medida em que faz-se necessário para tanto, possuir uma localização no mapa social, em outras palavras, "ter uma posição social reconhecida como legítima e situar-se num espaço físico compartilhado", como também, o sentimento de pertença, ou seja, "partilhar memórias e valores comuns, bem como sentimentos profundos de identificação" (ALVES; GONÇALVES, 2008, p. 108). A efetivação do direito fundamental à cidade acessível representa um 
fortalecimento da construção da emancipação ${ }^{9}$, pautada na relação entre a igualdade e o reconhecimento da diferença ${ }^{10}$, sendo condição de possibilidade para exercício da cidadania.

Um novo paradigma deve ser implementado quanto às políticas de atenção a pessoa com deficiência, requerendo desta feita a intervenção do Poder Público ${ }^{11}$ e da sociedade civil, com ênfase no exercício do poder ${ }^{12}$ por parte da pessoa com deficiência, para ser voz ativa na formulação de políticas de urbanização mais humanas. Daí, a tutela do ambiente urbano se perfazer no respeito a condição humana do outro e pela garantia do exercício da cidadania no espaço público, o que demanda uma adequação do espaço urbano não só para as presentes, mas para as futuras gerações.

Importante destacar, a existência de um direito à cidade, o direito de reivindicar e mudar a cidade e não apenas um direito de acesso ao que está posto. As cidades, não podem ser reduzidas à sua formação histórica, enquanto produto de apropriação da natureza e acumulação do capital, e sim, como ambiente necessário para promoção da cidadania. A promoção do direito à cidade, requer o acesso a um espaço público comum, desta feita, à participação política, necessária a construção e exercício da cidadania.

Contudo, como nos alerta Bauman (1999, p. 26):

Os espaços públicos - ágoras e fóruns nas suas várias manifestações, lugares onde se estabelecem agendas, onde assuntos privados se tornam públicos, onde opiniões são formadas, testadas e confirmadas, onde se passam julgamentos e vereditos - tais espaços seguiram as elites, soltando-se de suas âncoras locais; são os primeiros a se desterritorializar e mudar para bem além do alcance da capacidade comunicativa meramente de wetware de qualquer localidade e seus habitantes.

Os espaços públicos, agora “desterritorializados”, são inacessíveis, inalcançáveis para aquela parcela da população que teve a exclusão, a segregação, a imobilidade como espaço

\footnotetext{
${ }^{9}$ Como pondera GONTIJO; ARCELO, 2009, p. 5899, “(...) a hermenêutica do sujeito moderno demonstra que a liberdade do sujeito é seu instrumento de emancipação. Neste sentido, cabe ao sujeito moderno - por meio das técnicas de si (aspecto ético), da organização social e da resistência às prescrições institucionais que reproduzem a desigualdade (aspecto político), e da insurreição dos saberes sujeitados contra saberes hegemônicos excludentes (aspecto do saber) - produzir um contrapoder que afirme a complexidade das dimensões da personalidade na contemporaneidade".

${ }^{10}$ Nesse sentido, Boaventura de Sousa Santos identifica a necessidade de “(...) construir a emancipação a partir de uma nova relação entre o respeito da igualdade e o princípio do reconhecimento da diferença”. Para o autor, “(...) uma luta pela igualdade tem de ser também uma luta pelo reconhecimento da diferença, porque o importante não é a homogeneização mas as diferenças iguais" (SANTOS, 2007, p. 62/63).

11 Para Flávia Piovesan (2012, p. 411), “a responsabilidade do Estado na consolidação da cidadania está condicionada ao fortalecimento de estratégias que sejam capazes de implementar os três elementos essenciais à cidadania plena, quais sejam, a indivisibilidade e a universalidades dos direitos humanos e o processo de especificação do sujeito de direito.”.

12 "O exercício do poder deriva de métodos claramente estabelecidos de participação, incrementando, desta forma, a habilidade para exercer a autodeterminação, que, por sua vez, aperfeiçoa os níveis de exercício do poder” (CANZIANI, 2006, p. 259).
} 
reservado no ambiente urbano. Daí, por que, para o pensador polonês, "um território despojado de espaço público dá pouca chance para que as normas sejam debatidas, para que os valores sejam confrontados e negociados" (BAUMAN, 1999, p. 28). A redução dos espaços públicos ${ }^{13}$, e desses espaços como espaços de participação social deveu-se ao modelo de urbanização que privilegiou as fortificações e incomunicabilidade em razão da segurança, segurança das elites, frise-se, que por trás de suas fortificações esvaziaram esse ambiente artificialmente concebido. Manter-se isolado, evitar, separar, se apresenta como uma estratégia de sobrevivência nas grandes cidades, não havendo mais a necessidade de amar ou odiar o vizinho, tal dilema é afastado ao mantê-lo ao alcance das mãos (BAUMAN, 1999, p. 48).

O espaço comum ${ }^{14}$ também é trabalhado por Harvey, quando nos fala da criação dos bens comuns urbanos, para o pensador:

As qualidades humanas da cidade emergem de nossas práticas nos diversos espaços da cidade, mesmo que eles sejam passíveis de cercamento, controle social e apropriação, tanto pelos interesses privados como pelos públicos-estatais (HARVEY, 2014, p. 143).

O autor nos alerta ainda que a perda da comunalidade ${ }^{15}$ urbana, reflete a onda de privatizações, do cercamento e do controle espacial, que se dá através do policiamento e vigilância, na qualidade de vida urbana. Inibindo, especialmente, o surgimento de novos comuns, diante de um processo de urbanização dominado pelo interesse capitalista (HARVEY, 2014, p. 134). Ocorre que, enquanto a violação ao direito fundamental à cidade acessível persistir, impedindo assim, que a pessoa com deficiência participe de forma autônoma da vida urbana e de seus espaços comuns, essa permanece sem exercer sua cidadania de forma plena, o que fere princípios constitucionais basilares, como a dignidade da pessoa humana, liberdade, igualdade e inclusão social.

\footnotetext{
${ }^{13}$ Para ALVES; GONÇALVES, 2008, p. 112, “(...) o espaço público contemporâneo - física e espacialmente considerado - se caracteriza, cada vez mais, pela velocidade, pela circulação, pela comunicação e pelo consumo (v. g., aeroportos, centros comerciais, avenidas largas e rectilíneas)".

${ }^{14}$ Para David Harvey: “(...) o comum não deve ser entendido como um tipo específico de coisa, de ativo ou mesmo de processo social, mas como uma relação social instável e maleável entre determinado grupo social autodefinido e os aspectos já existentes ou ainda por criar do meio social e/ou físico, considerada crucial para sua vida e subsistência" (HARVEY, 2014, p. 145).

${ }^{15}$ Quanto à vida em comum, pontua Harvey: "Existe, de fato, uma prática social de comunalização. Prática que cria ou estabelece uma relação social com o comum cujos usos sejam tanto exclusivos de um grupo social quanto parcial ou totalmente abertos a todos. No cerne dessa prática de comunalização encontra-se o princípio de que a relação entre o grupo social e o aspecto do ambiente tratado como um comum será tanto coletivo quanto não mercantilizado - para além dos limites da lógica das trocas e avaliações de mercado. Esse último ponto é crucial, pois ajuda a distinguir entre bens públicos, entendidos como gastos produtivos do Estado, e um comum estabelecido ou usado de maneira totalmente diferente e com uma finalidade totalmente diferente, mesmo quando acabe fomentando indiretamente a riqueza e o lucro do grupo social que o reinvindica" (HARVEY, 2014, p. 145).
} 
Mesmo referindo-se a mobilidade espacial, como indicativo de promoção social, progresso e sucesso, a compreensão de Bauman quanto à imobilidade no espaço, é elucidativa.

\begin{abstract}
A imobilidade forçada, a condição de estar preso a um lugar, sem permissão de se mudar para parte alguma, parece abominável, cruel e repulsiva; é a proibição de movimento, mais do que a frustração de um efetivo desejo de mudar, que torna essa situação especialmente ofensiva. Estar proibido de mover-se é um símbolo poderosíssimo de impotência, de incapacidade e dor (BAUMAN, 1999, p. 116).
\end{abstract}

A imobilidade forçada num ambiente hostil à diversidade representa uma forma voraz de desrespeito aos direitos humanos e fundamentais da pessoa com deficiência, não ter a liberdade de opção de locomover-se de forma independente e autônoma pelo espaço urbano remonta aos instrumentos disciplinares e aos demais mecanismos de regulação da população que não parecem eliminados na contemporaneidade. Para Lafer $\left(1988\right.$, p. 204) ${ }^{16}$, "são inocentes condenados, destituídos de um lugar no mundo - um lugar que torne as suas opiniões significativas e suas ações efetivas".

O ambiente urbano pobre de espaços públicos reflete a realidade desses não-cidadãos, que se mantem invisíveis perante a indiferença da maioria da sociedade. Importante notar, que as liberdades são proclamadas partindo-se da perspectiva da pessoa humana como ser em busca da autorrealização, cabendo ao Estado Democrático guarnecer e estimular essas liberdades, inclusive através de medidas que assegurem maior igualdade entre todos, prevenindo que as liberdades tornem-se meramente formais ${ }^{17}$.

Jayme (2005, p. 47) enfatiza que os valores de igualdade e liberdade, elementos essenciais da democracia, remetem-se à ideia de justiça. Esse direito à redistribuição deve ser aliado ao direito ao reconhecimento, que, através de medidas de enfrentamento das injustiças socioeconômicas e culturais, que marginalizaram ao longo do tempo parcelas da população marcadas pela dicotomia do "eu versus o outro", busquem um ideal de justiça social. Daí por que, a necessidade e obrigatoriedade da Administração Pública em adotar medidas adequadas para garantir que as pessoas com e sem deficiência possam em igualdade de oportunidades viver

\footnotetext{
${ }^{16} \mathrm{O}$ excerto retirado da obra A reconstrução dos direitos humanos de Celso Lafer, refere-se aos apátridas, contudo, entendemos que o tratamento dado à pessoa com deficiência ao longo da história não se distancia do experimentado por outras categorias também consideradas supérfluas.

${ }^{17}$ Nessa direção, mas referindo-se à ideia de igualdade, esclarece Flávia Piovesan (2015b, p. 68): "Destacam-se, assim, três vertentes no que tange à concepção da igualdade: a) a igualdade formal, reduzida à fórmula "todos são iguais perante a lei" (que ao seu tempo, foi crucial para a abolição de privilégios); b) a igualdade material, corresponde ao ideal de justiça social e distributiva (igualdade orientada pelo critério socioeconômico); e c) a igualdade material, correspondente ao ideal de justiça enquanto reconhecimento de identidades (igualdade orientada por critérios como gênero, orientação sexual, idade, raça e etnias)".
}

Rev. de Direito Urbanístico, Cidade e Alteridade | e-ISSN: 2525-989X | Maranhão | v. 3 | n. 2 | p. 88 - 103 | Jul/Dez. 2017. 
com independência e participar plenamente de todos os aspectos de sua existência no espaço urbano.

Considerando-se o isolamento forçado da pessoa com deficiência, o que a impede de se locomover de forma autônoma pela cidade, e por conseguinte, de exercer sua cidadania, por não usufruir de espaços comuns, que são também espaços de participação, essa parcela da população permanece ausente e carente de representatividade nos espaços públicos, estando assim, duplamente impedida de reivindicar seu direito à cidade. O processo de afirmação dos direitos humanos, enquanto produto para convivência coletiva, requer a existência do espaço público, e a este espaço só se tem acesso pleno por meio da cidadania, e ainda, para fazer uso de tal direito, necessário se faz garantir a acessibilidade como condição primeira para o exercício da cidadania e, assim, exigir os direitos inerentes a condição humana.

Ocorre que, os excluídos da história, os mesmos que foram excluídos da cidade ideal, estigmatizados pelos dispositivos de diferenciação experimentados no ambiente urbano, "a partir da distinção geométrica centro/periferia, rapidamente transformada em metáfora da proximidade ao poder e em tabela de preços do solo" (FERNANDES; MEIRINHOS, 2008, p. 135) tiveram sua cidadania tomada. O modelo de urbanização experimentado ao longo dos séculos, tornou-se um símbolo da construção da cidade como não-lugar ${ }^{18}$, contudo, "a geografia e a geometria das cidades têm hoje uma palavra decisiva a dizer sobre a realização e o reconhecimento da pessoa humana no espaço público, no estabelecimento de laços sociais e as possibilidades de construção da sua cidadania” (ALVES; GONÇALVES, 2008, p. 117/118).

\section{CONCLUSÃO}

Os desafios para cidades acessíveis parecem irresolvíveis, entretanto, a participação da sociedade civil na propositura, confecção, implementação e fiscalização de políticas públicas, através dos instrumentos de participação social conquistados com o advento do Estatuto da Cidade (mesmo que a passos lentos e sem grandes avanços práticos, se considerarmos os dezesseis anos da regulamentação dos artigos que dispõe sobre a Política Urbana na Constituição Federal de 1988), apresenta-se como saída para uma política urbana que realize no presente, mas com vistas para as futuras gerações.

\footnotetext{
${ }^{18}$ Denominação antropológica cunhada por AUGÉ (1992), referindo-se a espaços que mesmo concebidos como espaços públicos ou de fluxo de pessoas, a exemplo dos centros comerciais, já nascem esvaziados de carga e laços simbólicos, por carecerem de construção identitária comum. V. ALVES; GONÇALVES, 2008, p. 115.
}

Rev. de Direito Urbanístico, Cidade e Alteridade | e-ISSN: 2525-989X | Maranhão | v. 3 | n. 2 | p. 88 - 103 | Jul/Dez. 2017. 
Importante notar, contudo, que o número e a positivação de instrumentos de participação social na gestão das cidades, por si só não são suficientes para sua efetivação. Para que essa participação não seja meramente simbólica ou mesmo não venha a existir, o que Boaventura de Sousa Santos denomina por "cidadania bloqueada"19, o Estado deve promover e assegurar a livre, significativa e ativa participação da $\operatorname{sociedade}^{20}$ na elaboração, implementação, bem como, monitoramento de políticas públicas de desenvolvimento.

É possível afirmar que, a maior capilaridade do poder local, leia-se, dos Municípios, é importante característica na busca pela participação social efetiva, fortalecendo, assim, a sociedade e construindo a cidadania. De toda sorte, vislumbra-se aqui, como alternativa, ou melhor, estratégia para cidades acessíveis, a gestão democrática das cidades. Mesmo que utópico, como nos alerta Lefebvre, parece ser um caminho para cidades mais humanas, onde a fala de diversos atores sociais por um direito à cidade tenha lugar, na formulação de programas e projetos de planejamento urbano que garantam a acessibilidade como um direito fundamental e inerente a condição humana, para as presentes e futuras gerações, por ser condição de possibilidade para o exercício da cidadania.

\section{REFERÊNCIAS}

ADEODATO, João Maurício. A retórica constitucional - sobre tolerância, direitos humanos e outros fundamentos éticos do direito positivo. São Paulo: Saraiva, 2010.

Retórica e a fundamentação ética dos direitos humanos. Direitos Humanos e Fundamentais em Perspectiva. Cláudio Brandão, coordenador. São Paulo: Atlas, 2014. Pp. $32-54$.

ALVES, Fernando Brandão; GONÇALVES, José Luís. Que rosto de lugar público na cidade competitiva? In: A Filosofia e a Cidade. Paula Crista Pereira, organização. Porto: Campo das Letras, 2008.

\footnotetext{
${ }^{19}$ Para o autor lusitano, uma cidadania que não garante as condições de participação, "uma cidadania que se baseia na ideia de participação mas não garante suas condições materiais.". Destaque-se também, que, para Boaventura de Sousa Santos, três condições são necessárias para poder participar, quais sejam: "temos de ter nossa sobrevivência garantida, porque se estamos morrendo de fome não vamos participa; temos de ter um mínimo de liberdade para que não haja uma ameaça quando vamos votar; e finalmente temos de ter acesso à informação" SANTOS, 2007, p. 92.

${ }^{20}$ Tratando dos desafios contemporâneos para o direito ao desenvolvimento, Flávia Piovesan destaca a participação enquanto componente essencial ao direito ao desenvolvimento, para autora: "É dever dos Estados encorajar a participação popular em todas as esferas como um importante fator ao direito ao desenvolvimento e à plena realização dos direitos humanos" (PIOVESAN, 2012, p. 159).
}

Rev. de Direito Urbanístico, Cidade e Alteridade | e-ISSN: 2525-989X | Maranhão | v. 3 | n. 2 | p. 88 - 103 | Jul/Dez. 2017. 
ALVES, J. A. Lindgren. Os direitos humanos na pós-modernidade. São Paulo: Perspectiva, 2005 .

ARAUJO, Luiz Alberto David. A proteção constitucional das pessoas com deficiência e o cumprimento do princípio da dignidade da pessoa humana. In: MIRANDA, Jorge; SILVA, Marco Antonio Marques da (Coord.). Tratado Luso-Brasileiro da Dignidade Humana. São Paulo: Quartier Latin, 2008. Pp. 205-211.

BAUMAN, Zygmunt. Globalização: as conseqüências humanas. Tradução: Marcus Penchel. Rio de Janeiro: Jorge Zahar Ed., 1999.

BOBBIO, Norberto. A era dos direitos. Rio de Janeiro: Elsevier, 2004. 13 ${ }^{\mathrm{a}}$ reimpressão.

CANZIANI, Maria de Lourdes. Direitos humanos e os novos paradigmas das pessoas com deficiência. In: ARAUJO, Luiz Alberto David (coord.). Defesa dos direitos das pessoas portadoras de deficiência. São Paulo: Revista dos Tribunais, 2006. Pp. 250-262.

DIEGUES, Geraldo César. A Construção da Participação Social na Gestão das Políticas Públicas: O Protagonismo do Governo Local no Brasil. Administração Pública e Gestão Social, [S.1.], v. 4, n. 4, p. 365-380, dez. 2012. ISSN 2175-5787. Disponível em: <http://www.apgs.ufv.br/index.php/apgs/article/view/115/199>. Acesso em: 21 jun. 2017.

FARIAS, José Fernando de Castro. A origem do direito de solidariedade. Rio de Janeiro, Renovar: 1998.

FERNANDES, José A. Rio; MEIRINHOS, José Francisco. Cidades ideais, ideais de cidade, cidades reais. In: A Filosofia e a Cidade. Paula Crista Pereira, organização. Porto: Campo das Letras, 2008.

FONSECA, Ricardo Marcelo. Introdução teórica à história do direito. Curitiba: Juruá, 2012.

GONTIJO, Lucas de Alvarenga; ARCELO, Adalberto Antonio Batista. A biopolítica nos estados democráticos de direito: a reprodução da subcidadania sob a égide da constitucionalização simbólica. In: Anais do XVIII Congresso Nacional do CONPEDI, realizado em São Paulo - SP nos dias 04, 05, 06 e 07 de novembro de 2009. Disponível em: <http://www.publicadireito.com.br/conpedi/manaus/arquivos/Anais/sao_paulo/2412.pdf. $>$. Acesso em: 27 jun. 2017.

HARVEY, David. Cidades rebeldes: do direito à cidade à revolução urbana. São Paulo: Martins Fontes - selo Martins, 2014.

HESPANHA, António Manuel. A cultura jurídica europeia. Coimbra: Almedina, 2012.

JAYME, Fernando G. Direitos humanos e sua efetivação pela corte interamericana de direitos humanos. Belo Horizonte: Del Rey, 2005.

LAFER, Celso. A reconstrução dos direitos humanos: um diálogo com o pensamento de Hannah Arendt. São Paulo: Companhia das Letras, 1988.

Rev. de Direito Urbanístico, Cidade e Alteridade | e-ISSN: 2525-989X | Maranhão | v. 3 | n. 2 | p. 88 - 103 | Jul/Dez. 2017. 
LEFEBVRE, Henri. O direito à cidade. São Paulo: Centauro, 2001.

MAGALHÃES, José Luiz Quadros de. Plurinacionalidade e cosmopolitismo: a diversidade cultural das cidades e diversidade comportamental nas metrópoles. In: Revista de Direitos e Garantias Fundamentais, Vitória, n. 7, p. 203-216, jan./jun. 2010. Disponível em: $<$ http://sisbib.fdv.br/index.php/direitosegarantias/article/viewFile/84/80 >. Acesso em: 19 jun. 2017.

MARQUES, Clarissa. Meio ambiente, Solidariedade e Futuras gerações. Nomos: Revista do Programa de Pós-graduação em Direito da UFC, vol. 32.2, jul./dez.2012. Disponível em: $<$ http://www.periodicos.ufc.br/index.php/nomos/article/viewFile/348/330>. Acesso em: 23 mai. 2015.

. O conceito de direitos fundamentais. Direitos Humanos e Fundamentais em

Perspectiva. Cláudio Brandão, coordenador. São Paulo: Atlas, 2014.

PIOVESAN, Flávia. Direitos humanos e justiça internacional: um estudo comparativo dos sistemas regionais europeu, interamericano e africano. 6 ed. rev., ampl., e atual. São Paulo: Saraiva, 2015.

. Temas de direitos humanos. 5 ed. São Paulo: Saraiva, 2012.

PRADO, Adriana Romeiro de Almeida. Acessibilidade na gestão da cidade. In: ARAUJO, Luiz Alberto David (coord.). Defesa dos direitos das pessoas portadoras de deficiência. São Paulo: Revista dos Tribunais, 2006. Pp. 09-29.

SANTOS, Boaventura de Sousa. Renovar a teoria crítica e reinventar a emancipação social. Tradução Mouzar Benedito. São Paulo: Boitempo, 2007.

WOLKMER, Antonio Carlos. História do Direito no Brasil. Rio de Janeiro: Forense, 2004.

WOLKMER, Antonio Carlos. Marx, a questão judaica e os direitos humanos. Seqüiência: Estudos Jurídicos e Políticos, Florianópolis, p. 11-28, jan. 2004. ISSN 2177-7055. Disponível em: 〈https://periodicos.ufsc.br/index.php/sequencia/article/view/15230〉. Acesso em: $04 \mathrm{fev}$. 2016.

Rev. de Direito Urbanístico, Cidade e Alteridade | e-ISSN: 2525-989X | Maranhão | v. 3 | n. 2 | p. 88 - 103 | Jul/Dez. 2017. 